\title{
Party at The Mailbox: A Celebration of Community
}

\author{
MELISSA R. MICHELSON | MENLO COLLEGE
}

SARAH V. HAYES | UNIVERSITY OF CALIFORNIA, RIVERSIDE

STEPHANIE L. DEMORA | UNIVERSITY OF CALIFORNIA, RIVERSIDE

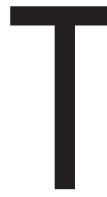

The 2020 elections took place amidst two pandemics: a new one caused by the coronavirus, and an ongoing one caused by racism, both of which impacted engagement in the 2020 elections. By mid-March, the country was locked down in an attempt to slow down the spread of COVID-19. On May 25, George Floyd was murdered. Meanwhile, state and local governments sought ways to finish the primary election season and make plans for the general election. Our project-Party at the Mailbox (PATM) - worked at the intersection of all three.

Designed and led by Black Girls Vote, and conducted in collaboration with other local organizations, including Black-led organizations, Party at the Mailbox worked to increase Black voter turnout while maintaining pandemic safety protocols and recognizing the increased use of vote-by-mail ballots. Together, we built on local initiatives and experience to build a large, robust get-out-the-vote effort that was owned by local community organizations, intentionally guided by local experts, and encouraged voters to return their vote-by-mail ballots.

Our academic team worked behind the scenes to ensure the effort was rigorous and included a randomized controlled trial (RCT) for evaluation purposes. The on-the-ground feeling was one of local grassroots organizations talking to their communities. Centering local expertise paid off: our RCT showed an increase in participation in the Baltimore June primary of 12.4 percentage points (from 19\% in the control group to $31.4 \%$ in the treatment group) among low propensity voters-and that does not even take into account the spillover effects in terms of increases in turnout by friends and neighbors, the enhanced feeling of community and belonging generated by the program, and capacity building among our partner organizations that will continue to reap benefits in downstream elections. For the general election in November, we expanded to three cities: Baltimore, Detroit, and Philadelphia.

Melissa R. Michelson is Dean of Arts \& Sciences and professor of political science at Menlo College. Her academic work is solidly based in activist scholarship.

Sarah Hayes is a graduate student in the political science department at the University of California, Riverside. Broadly, her research interests are Black politics, political behavior, electoral politics, and health policy.

Stephanie L. DeMora is a PhD candidate at the University of California, Riverside where her main focuses are mass political behavior and American politics.

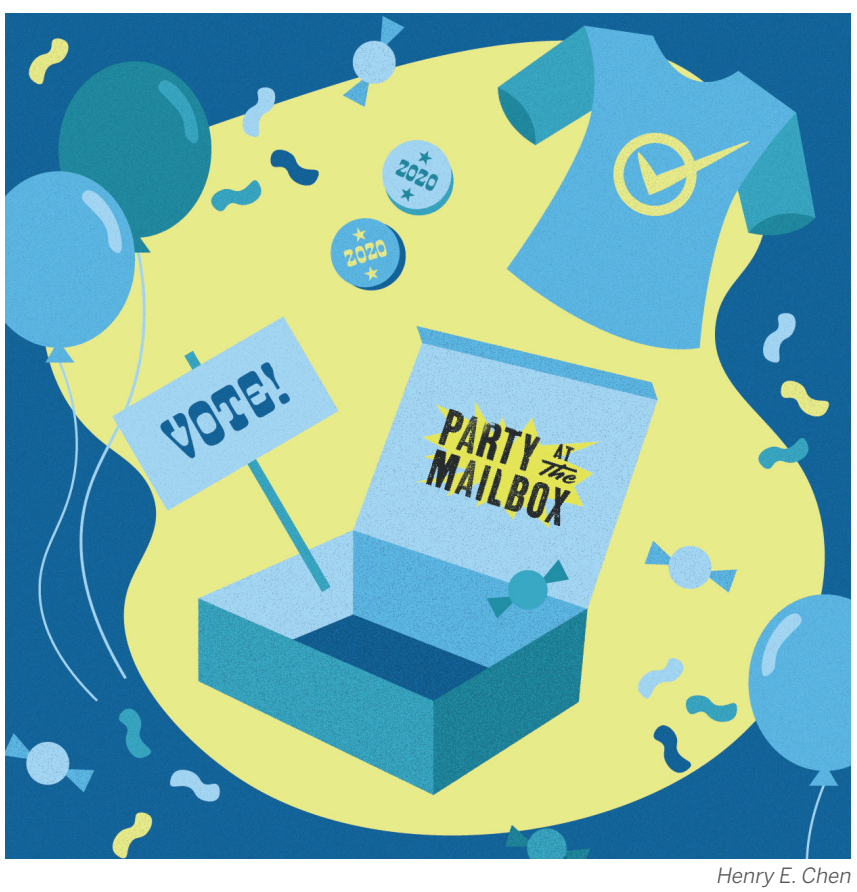

Individuals in each city who signed up at Party at the Mailbox received a box of informative voting materials and goodies including a t-shirt, a coloring book and crayons, local treats, a noisemaker and confetti, stickers and buttons, and other gifts. But as founder of the program Nykidra Robinson likes to say, "it's not just a box, it's an experience." Robinson's electoral mobilization strategy centered community celebration through collective organizing and togetherness. A pivotal aspect of PATM was recognizing the necessity of community support while confronting these two pandemics in a safe, yet joyous, manner.

With local treats and artwork, each box was a true representation of the community. Eateries and artists provided baked goods, GOTV signs, and creative t-shirt designs. The boxes were delivered by hand, often in a van wrapped with PATM graphics and information. Local community organizations were given subgrants to promote the program while supporting local residents (e.g., food giveaways). Fostering community spirit was deeply embedded in the campaign. Voters felt the box was a celebration of their city and expressed their excitement to vote for a better future. As boxes began to be delivered (and unboxed in Instagram videos), excitement grew. Local news stations, organizations, and leaders actively participated in the 
campaign, furthering community engagement.

In addition to randomized controlled trials, we collected evaluation data using a survey, interviews with voters and partner organization leaders, and Zoom focus groups in each city. Our qualitative interviews with voters documented the creative ways in which voters were using the materials in their boxes. Some voters used this as an opportunity to decorate their community gardens, while others drove through their neighborhoods with posters attached to their cars. Most surprisingly, many voters used their boxes to spread election awareness within their digital networks. Most of the individual voters who engaged with PATM

The results are exciting not only for how they document the power of community-led and ground efforts, but because they mark a crucial contribution to our understanding of how best to get out the

Black American vote.

were Black Americans. This reflects the identity and background of Black Girls Vote founder and CEO Nykidra Robinson, and is an intentional centering of the program in Black communities and with Black-led community partners. As a result, while PATM engaged with voters of a variety of racial backgrounds, it gave Black voters in particular the ability to feel connected in such a critical moment.

Facing two pandemics, Black Americans not only witnessed health inequalities in COVID-19 cases, but also an increased national attention on racism. Robinson's vision for PATM and her broader organizing efforts illustrate what Black organizing looks like-adapting to difficult circumstances while still keeping celebration in mind. While community togetherness remains a central component to increasing voter turnout, the arenas and mechanisms in which it happens are shifting. PATM has shown that community collectiveness, even digitally, can produce pow-

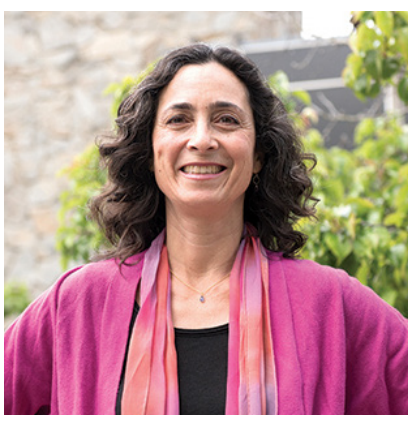

Melissa R. Michelson

erful effects.

Turnout in the November 2020 election broke records, with high turnout among voters of all races and partisan identities. Beyond these background increases in turnout, however, we document spikes in participation clearly linked to the PATM program. The results are exciting not only for how they document the power of commu-

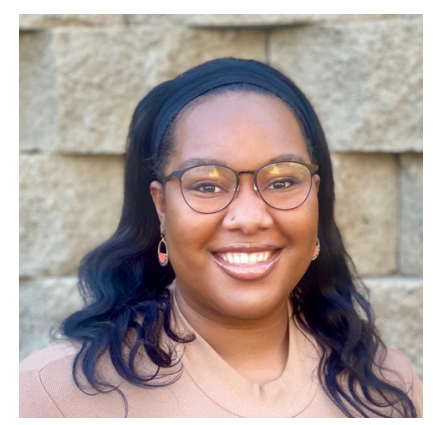

Sarah Hayes

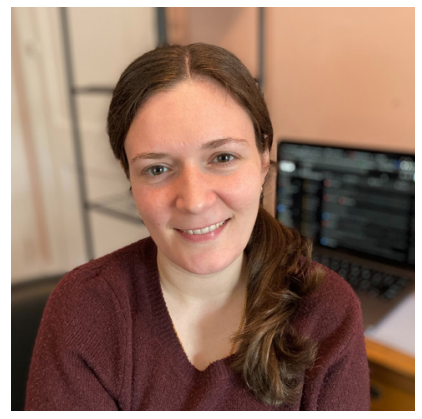

Stephanie L. DeMora nity-led and ground efforts, but because they mark a crucial contribution to our understanding of how best to get out the Black American vote. For years, scholars who focus on turnout and GOTV in historically marginalized communities have argued that these efforts must be grounded in year-round community building and trusted local organizations. Yet, few efforts have heeded those best practices and trusted local organizations, particularly Black-led organizations, to do the work. Our partnership with Black Girls Vote and other local organizations flipped the switch and let these local experts take the lead. The results of our efforts further inform us on how Black organizing is changing and how political scientists are theorizing GOTV efforts.

\section{APSA DOCTORAL DISSERTATION RESEARCH IMPROVEMENT GRANTS}

The DDRIG project provides support to enhance and improve the conduct of doctoral dissertation research in political science.

Applications due June 15, 2020.

Apply at: https://bit.ly/3e3426I
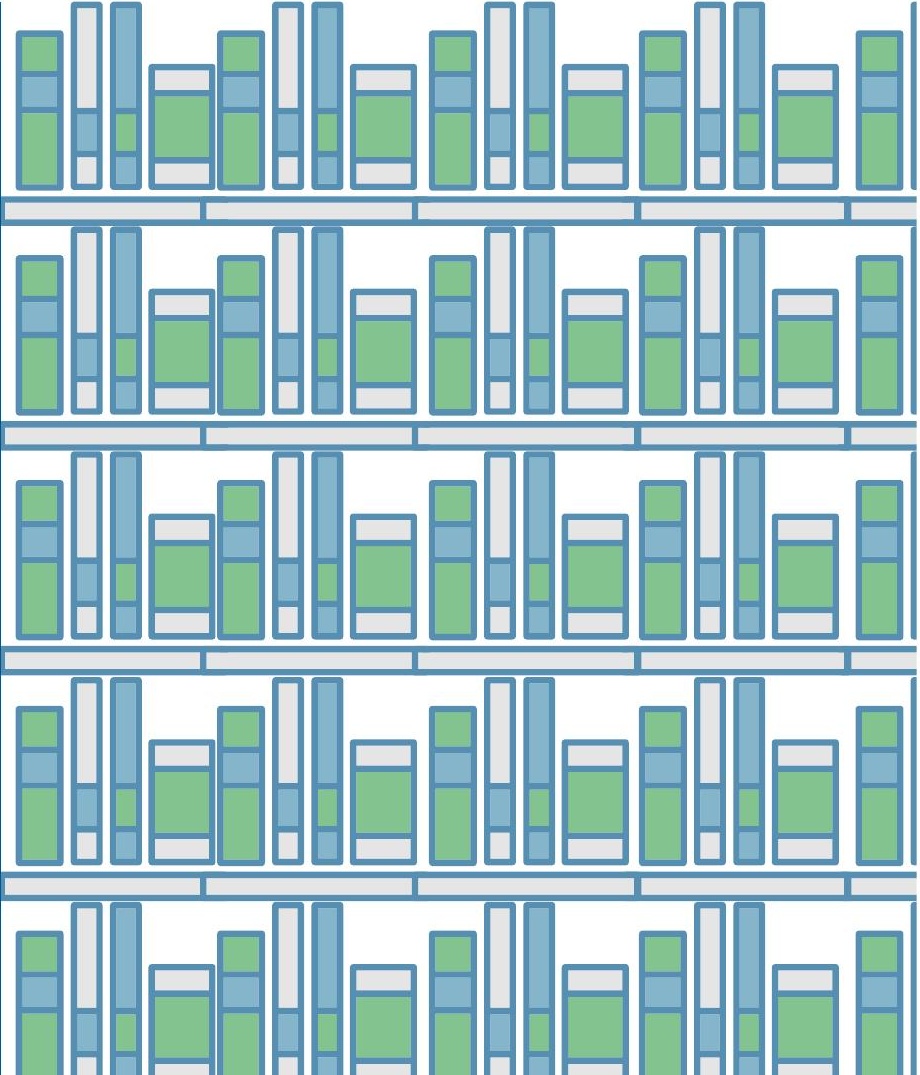


\section{Join an APSA Organized Section}

Organized sections provide an opportunity for groups of APSA members who share a common interest in a particular subfield to organize meetings and coordinate communications.

Join a section by logging into your account at apsanet.org, clicking your name at the top of the page and selecting the green "Add a Section" button. See a full list of sections at www.apsanet.org/sections.
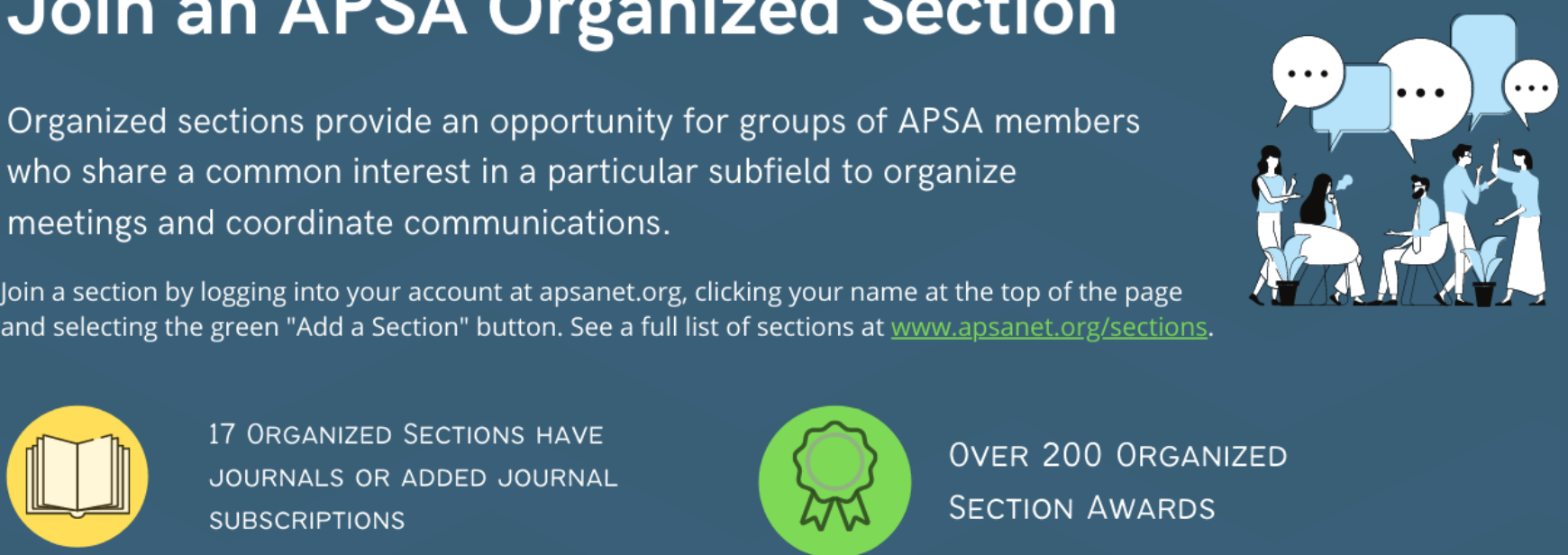

17 ORgANIZED SECTIONS HAVE JOURNALS OR ADDED JOURNAL SUBSCRIPTIONS

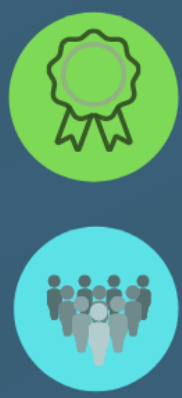

OVER 200 ORGANIZED SECTION AWARDS

34 ORgANIZED SECTIONS WAIVE STUDENT DUES

$75 \%$ OF APSA MEMBERS BELONG TO AT LEAST ONE ORGANIZED SECTION

\section{Join an APSA Related Group}

APSA Related Groups are professional groups, engaged in the study of political science. Related Groups add diversity and represent a broad spectrum of civic and political issues. Groups also host panels, workshops, and receptions at the APSA Annual Meeting.

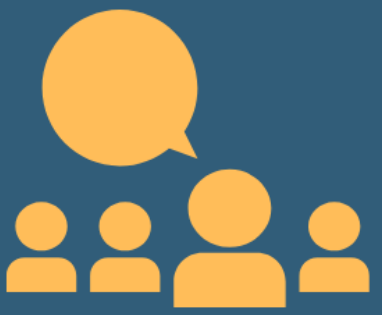
www.apsanet.org/RESOURCES/Related-Groups

\begin{tabular}{|c|c|c|}
\hline $\begin{array}{l}\text { Related Groups include: } \\
\text { - subject matter groups } \\
\text { - caucuses } \\
\text { - identity groups } \\
\text { - think tanks } \\
\text { - nonprofits } \\
\text { - other academic } \\
\text { associations }\end{array}$ & $\begin{array}{c}45 \text { Related } \\
\text { Groups and no } \\
\text { additional fees } \\
\text { to join! }\end{array}$ & $\begin{array}{l}\text { Login to your account at } \\
\text { apsanet.org, click your } \\
\text { name at the top of the page } \\
\text { and select Related Groups } \\
\text { on the right hand side to } \\
\text { add a group. }\end{array}$ \\
\hline
\end{tabular}

